\title{
ELECTROANALYTICAL DETERMINATION OF CODEINE IN PHARMACEUTICAL PREPARATIONS
}

\author{
Jorge M. P. J. Garrido, Cristina Delerue-Matos, Fernanda \\ Borges, Tice R. A. Macedo, \\ and A. M. Oliveira-Brett
}

\begin{abstract}
A square wave voltammetric (SWV) method and a flow injec- tion analysis system with electrochemical detection (FIA-EC) using a glassy carbon electrode were evaluated for the deter- mination of codeine in pharmaceutical preparations. The interference of several compounds, such as acetaminophen,

guaiacol, parabens, ephedrine, acetylsalicylic acid and caffeine, that usually appear associated with codeine pharma- ceutical preparations was studied. It was verified that these electroanalytical methods could not be used with acetamino- phen present in the formulations and that with guaiacol, parabens or ephedrine present the use of the FIA-EC system was impracticable. A detection limit of $5 \mathrm{mmol} \mathrm{L}^{-1}$ and a linear calibration range from 40 to $140 \mathrm{mmol} \mathrm{L}^{-1}$ was obtained with the SWV method. For the flow injection analysis procedure a linear calibration range was obtained from 7 to $50 \mathrm{mmol} \mathrm{L}^{-1}$ with a detection limit of $3 \mathrm{mmol}$ $\mathrm{L}^{-1}$ and the FIA-EC system allowed a sampling rate of 115 samples per hour. The results obtained by the two methods, SWV and FIA-EC, were compared with those obtained using reference methods and demonstrated good agreement, with relative deviations lower than $4 \%$.
\end{abstract}

Key Words

Codeine; Square wave voltammetry; Flow injection analysis with electrochemical detection; Acetamino- phen; Guaiacol; Parabens; Ephedrine; Acetylsalicylic acid; Caffeine 
effective analgesic and antitussive agent in pharmaceutical pre- parations. Some of the common side effects associated with the use of codeine include drowsiness, lightheadedness, dry mouth and, of course, euphoria. Since codeine belongs to the opiate group, whose more important

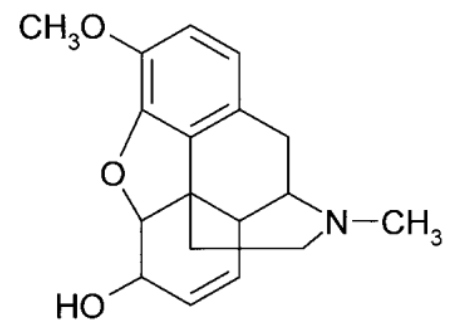

Figure 1. Structure of codeine.

effects are on the central nervous system, it can produce psychological dependence and is one of the main limitations of its clinical use.

A sensitive and specific analytical method is therefore essential for studying the bioavailability of codeine from oral formulations. Surprisingly, relatively few procedures have been proposed for the determi- nation of codeine. Assay methods reported in the British ${ }^{[1]}$ and United States ${ }^{[2]}$ Pharmacopoeias are based on extraction of the base followed by non- aqueous titrimetry and HPLC. Other techniques for determining codeine include spectrophotometry, ${ }^{[3]}$ spectrofluorimetry, ${ }^{[4]}$ potentiometry ${ }^{[5,6]}$ and gas chromatography. ${ }^{[7]}$ Electrochemical methods for the determination of codeine are also described in the literature but they involve derivatization prior to the use of differential pulse polarography ${ }^{[8]}$ and the use of a Nafion/ruthenium oxide pyrochlore chemically modified electrode. ${ }^{[9]}$ Many of these methods require several manipulation steps such as liquid- liquid extraction, which are time consuming and solvent-usage intensive, plus sophisticated instrumentation and training. In order to quantify the bioavailability of codeine from oral formulations this paper reports the development of an electroanalytical methodology appropriate for routine analysis. A square-wave voltammetric (SWV) method and a flow injection analysis with electrochemical detection (FIA-EC) system for the determina- tion of codeine in commercial pharmaceutical preparations using a glassy carbon electrode will be described.

\section{EXPERIMENTAL SECTION}

\section{Apparatus}

For the voltammetric measurements a $663 \mathrm{VA}$ Metrohm cell containing a glassy carbon working electrode (Metrohm, d $d^{1 / 4} 2.0 \mathrm{~mm}$ ), a glassy carbon rod counter electrode (Metrohm) and an $\mathrm{Ag} / \mathrm{AgCl}(3 \mathrm{~mol} \mathrm{~L}-\mathrm{KCl})$ reference electrode (Metrohm) attached to an Autolab PSTAT 10 potentio- stat/galvanostat running with model GPES (EcoChimie, Netherlands).

The FIA system developed consists of a Gilson Minipuls 3 peristaltic pump to propel the solutions, a Rheodyne 5020 valve to inject the solutions and as detector unit an electrochemical system consisting of a VA 641 Metrohm detector and a 656 Metrohm electrochemical wall-jet cell. The cell consists of three electrodes: a Metrohm glassy carbon electrode as the working electrode a Metrohm gold electrode as the auxiliary electrode and a Metrohm $\mathrm{Ag} / \mathrm{AgCl}\left(3 \mathrm{~mol} \mathrm{~L}^{-1} \mathrm{KCl}\right)$ as the reference electrode. To link the different components of the FIA set-up, Omnifit Teflon tubing ( $0.8 \mathrm{~mm}$ i.d.) and Gilson end fittings were used. Additional home-made dampers 
were

used as described elsewhere. ${ }^{[10]}$ To record analytical signals, a Kipp \& Zonen (model BD 112) data recorder was used.

The glassy carbon working electrodes were manually cleaned and polished with abrasive every day, first with $1 \mathrm{~mm} \mathrm{Al} 2 \mathrm{O} 3(\mathrm{BDH})$ and then with deionised water only.

A Metrohm E520 pH-meter was used for the $\mathrm{pH}$ measurements.

For the HPLC reference method, ${ }^{[1]}$ a Sykam model A 1210 liquid chromatograph, equipped with a UV visible detector $\left(A^{1} 1 / 4285 \mathrm{~nm}\right)$ model 3200 was used. Separation of sample components was accomplished using a Nucleosil 100-10 C18 column ( $250 \times 4 \mathrm{~mm}, 10 \mathrm{~mm}$ particle size, Macherey- Nagel, Germany). The separation was carried out at room temperature using $0.01 \mathrm{~mol} \mathrm{~L}^{-1}$ sodium octanesulphonate in a mixture of 55 volumes of water, 45 volumes of methanol, and 1 volume of glacial acetic acid as the mobile phase with a flow rate of $1 \mathrm{~mL}$ per minute.

\section{Reagents and Solutions}

Analytical grade reagents were used without any additional purifica- tion. Deionised water with conductivity less than $0.1 \mathrm{mS} \mathrm{cm}^{-1}$ was used throughout. The $\mathrm{pH} 3$ acetate buffer used for the voltammetric determina- tions was prepared by dilution to $100 \mathrm{~mL}$ of $3.7 \mathrm{~mL}$ of $0.2 \mathrm{~mol} \mathrm{~L}^{-1} \mathrm{NaOAc}$ and $46.3 \mathrm{~mL}$ of $0.2 \mathrm{~mol} \mathrm{~L}^{-1}$ HOAc. The supporting electrolyte used as car- rier in the FIA system was prepared by dilution to $100 \mathrm{~mL}$ of $6.2 \mathrm{~mL}$ of $0.2 \mathrm{~mol} \mathrm{~L}^{-1} \mathrm{~K}_{2} \mathrm{HPO}_{4}$ and $43.8 \mathrm{~mL}$ of $0.2 \mathrm{~mol} \mathrm{~L}^{-1} \mathrm{KH}_{2} \mathrm{PO} 4$. For the HPLC reference method all the solvents used were of HPLC grade. Prior to use, the solvents were filtered and the air removed with helium.

\section{Standard and Sample Preparation}

Codeine stock solutions $\left(10^{-3} \mathrm{~mol} \mathrm{~L}^{-1}\right)$ were prepared by dissolution of weighed amounts of codeine hydrochloride (Uquipa, Portugal) in

$0.01 \mathrm{~mol} \mathrm{~L}^{-1} \mathrm{HClO}_{4}$. For the voltammetric method accurate volumes of the solution obtained were added in the cell to the buffer in order to obtain codeine concentrations between 40 and $140 \mathrm{mmol} \mathrm{L}^{-1}$. For the FIA system, more diluted solutions, between 7 and $50 \mathrm{mmol} \mathrm{L}^{-1}$, were prepared by careful dilution of the stock solution. All these solutions were prepared daily.

The determination of codeine was performed in commercial tablets and oral solutions available in Portugal and Belgium. The dosage forms analysed were SEDOTUSSE oral solution (Helfarma, Portugal), 
VACALIBOM oral solution (Moreno, Portugal), DOLVIRAN tablets (Bayer, Portugal), CODIS tablets (Reckitt \& Colman, Belgium) and NOGRIMINE tablets (Omega Pharma, Belgium). The nominal content of the labelled codeine is in Table 1, and the preparation of the samples for analysis was carried out as follows. Ten tablets were powdered in an agate mortar, homogenised and an appropriate amount, enough to obtain a con- centration within the calibration curve range, was carefully weighed and dissolved in $0.01 \mathrm{~mol} \mathrm{~L}^{-1} \mathrm{HClO} 4$. Oral solutions were just diluted with

$0.01 \mathrm{~mol} \mathrm{~L}^{-1} \mathrm{HClO} 4$ to achieve the appropriate concentration.

\section{RESULTS AND DISCUSSION}

\section{Effect of $\mathrm{pH}$}

Considering the structure of codeine it is surprising that until the middle $80 \mathrm{~s}$ it was considered non-electroactive and at present only a few electroanalytical studies are reported.

The electrochemical oxidation behaviour of codeine was studied using a glassy carbon electrode over a very wide $\mathrm{pH}$ range by differential pulse voltammetry, Fig. 2. The oxidation always occurs at very high positive potentials and is thus impossible to study using platinum or gold as working electrodes.

The oxidation mechanism of codeine is complex with adsorption occurring at the electrode surface and is also $\mathrm{pH}$ dependent. Three oxidation peaks were observed corresponding to the different groups in the molecule, shown in Fig. 1. Due to the very high positive potentials the detection of the peaks with higher potentials is limited by solvent evolution. At very acid $\mathrm{pH}$ only one oxidation peak can be observed. For $\mathrm{pH}$ values between 4 and 7 two oxidation peaks occurs and at $\mathrm{pH}>8$ three peaks can be detected. The position of all peaks was $\mathrm{pH}$ dependent and with a slope of $59 \mathrm{mV}$ per $\mathrm{pH}$ unit. The same number of electrons and protons are involved in the oxidation mechanism and the $\mathrm{pK} "$ "'9. Considering the current for the first oxidation peak, Fig. 2, it reaches the maximum value for $\mathrm{pH}^{1 / 4} 6$.

\section{Square Wave Voltammetry}

Square wave voltammetry (SWV) is a voltammetric technique that has better sensitivity than DPV and enables more rapid determinations and was chosen for establishing a voltammetric methodology for the determination of codeine in pharmaceutical preparations. As seen in Fig. 2 the oxidation of 


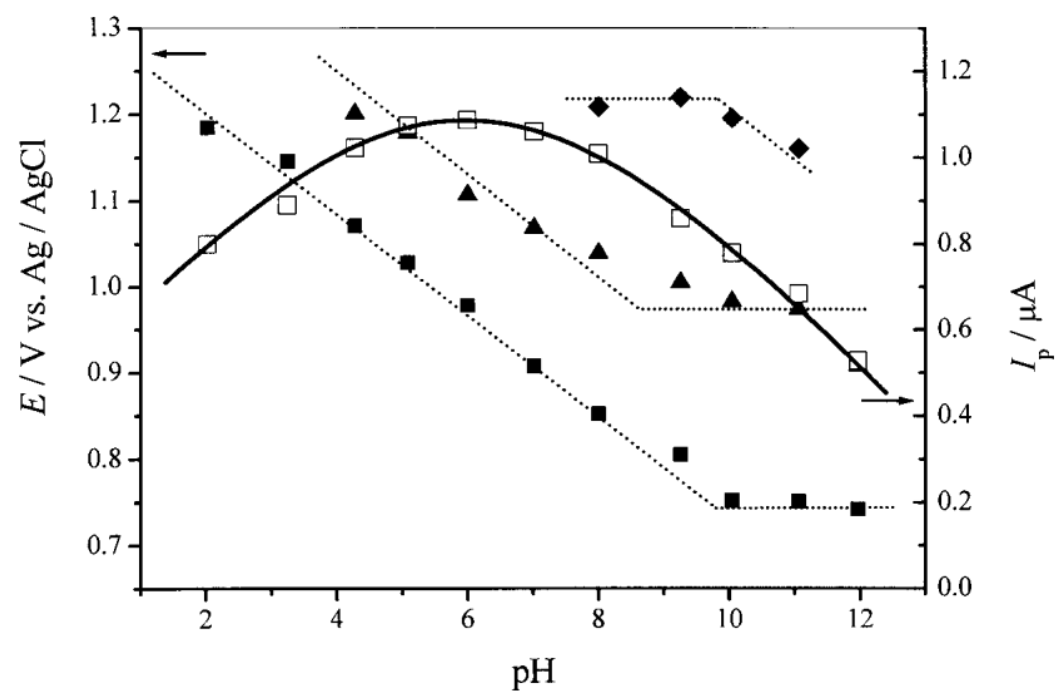

Figure 2. Plots of $E_{p}$ and $I p$ vs. pH from differential pulse voltammograms of $0.1 \mathrm{mmol} \mathrm{L}-1$ solutions of codeine in $0.2 \mathrm{~mol} \mathrm{~L}^{-1}$ ionic strength buffer electrolyte: $(\mathbf{g})$ first peak; $(\mathbf{m})$ second peak; $\left({ }^{\wedge}\right)$ third peak. Scan rate $5 \mathrm{mV} \mathrm{s}^{-1}$. Slope of dotted line $59 \mathrm{mV} / \mathrm{pH}$ unit.

codeine is a complex mechanism and three oxidation peaks can be observed at high $\mathrm{pH}$. This led to the selection of $\mathrm{pH} 1 / 43$, where only one peak appears, for the SWV electroanalytical determinations.

The optimal experimental SWV parameters were deduced: frequency, $f^{1 / 4} 150 \mathrm{~Hz}$, pulse amplitude, $E_{\mathrm{S}} 1 / 450 \mathrm{mV}$ and solution ionic strength, $I^{1 / 4} 0.2 \mathrm{~mol} \mathrm{~L}^{-1}$ and good linearity was obtained in the range of $40-140 \mathrm{mmol} \mathrm{L}^{-1}$ codeine, Fig. 3. The detection limit, evaluated as the con- centration of codeine corresponding to three times the standard deviation of the background signal, ${ }^{[11]}$ was found to be $5 \mathrm{mmol} \mathrm{L}^{-1}$.

\section{Flow Injection Analysis with Electrochemical Detection}

Flow injection analysis with electrochemical detection (FIA-EC), compared with stationary or continuous flow hydrodynamic voltammetry, has the advantage of a drastic decrease in adsorption associated with the use of a flow system. Since it was found, from the differential pulse voltammetric study, Fig. 2, that the highest current for the first oxidation peak was obtained at $\mathrm{pH} 6$ this buffer was chosen as supporting electrolyte. 


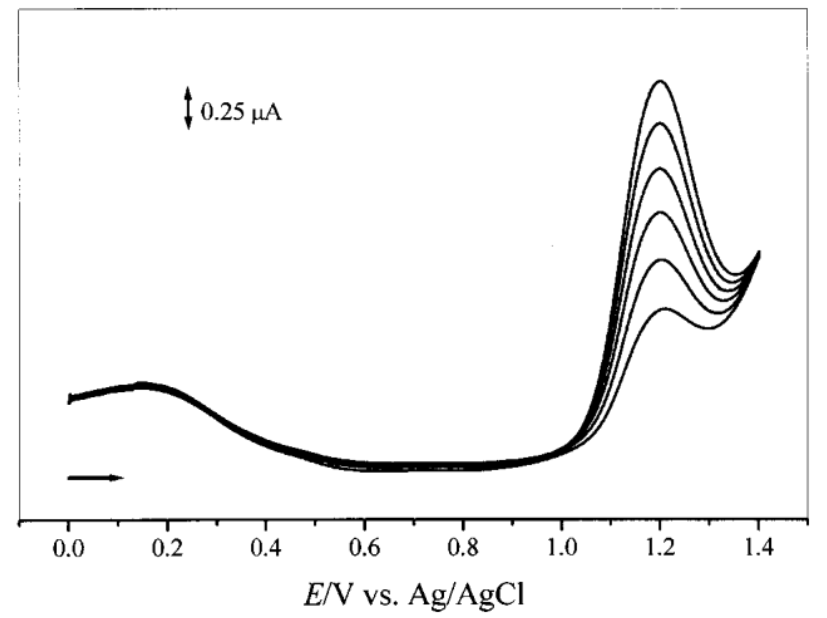

Figure 3. Successive square wave voltamograms in $\mathrm{pH} 30.2 \mathrm{~mol} \mathrm{~L}^{-1}$ buffer electrolyte of codeine: 41.4, 61.8, 82.0, 102.0, 121.8, and $141.4 \mathrm{mmol} \mathrm{L}^{-}$ 1 . Frequency $150 \mathrm{~Hz}$; pulse amplitude $50 \mathrm{mV}$.

The FIA manifold used in the determination of codeine was gradually optimised by the univariant method with the purpose of allowing the intro- duction of samples without pre-treatment and maximising the sample rate and reproducibility. Hence, a single channel manifold was set up (Fig. 4) and the influence of several parameters, namely the $\mathrm{pH}$ of supporting electrolyte, the working electrode potential, the flow rate $(Q 1)$, the injection volume $(A)$, and the length of the reactor $(R)$ was assessed. The study of the best working conditions of the FIA manifold was made using a $100 \mathrm{mmol} \mathrm{L}^{-1}$ solution of codeine.

The potential of the working electrode was optimised studying the variation of the current peak height with an applied fixed potential between p1.0 and p1.5 V. The peak current increased until a maximum at the applied potential of $\mathrm{p} 1.3 \mathrm{~V}$ and above this the peak remained virtually constant. Thus the value of $\mathrm{p} 1.3 \mathrm{~V}$ was chosen and used in subsequent trials.

The selection of the most adequate flow rate was dependent on limita- tions of the wall-jet cell whose dead volume is about $1 \mathrm{~mL} .^{[12]}$ It was verified that using flow rates higher than $2.4 \mathrm{~mL} \mathrm{~min}^{-1}$ was not satisfactory since they produce high pressures within the system, and consequently irreproducible signals, whereas lower flow rates gave reproducible signals but they compro- mise the sampling rate. Therefore, the value of 2.4 $\mathrm{mL} \mathrm{min}^{-1}$ was chosen. 


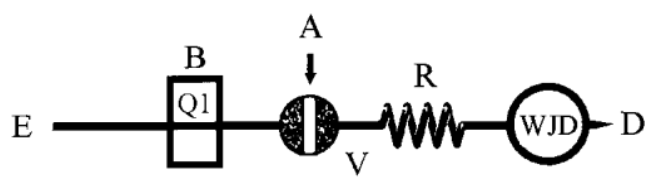

Figure 4. Flow injection analysis manifold used for codeine determination: Asample, B-peristaltic pump, E-inlet for $\mathrm{K}_{2} \mathrm{HPO}_{4} / \mathrm{KH}_{2} \mathrm{PO} 4$ buffer support electrolyte, Q1-flow rate $2.4 \mathrm{~mL} \mathrm{~min}^{-1}, \mathrm{~V}$-injection valve $(78 \mathrm{~mL}), \mathrm{R}$-mixing coil

$(30 \mathrm{~cm})$, WJD — wall-jet electrochemical detector, D_outlet for waste.

With the purpose of optimising the injection volume, loops were made of the same Teflon tubing that was used for the other parts of the system $(0.8 \mathrm{~mm}$ i.d.) with lengths between 5 and $15 \mathrm{~cm}$. A $10 \mathrm{~cm}$ loop was selected since higher injection volumes compromised sampling rate while lower ones produced less reproducible analytical signals. Theinjection volume, which was afterwards determined by titration of a solution of known concentration, ${ }^{[13]}$ corresponded to $78 \mathrm{~mL}$.

The optimisation was concluded with the selection of the reactor length in which the mixture of the sample plug with the electrolyte takes place. Reactors with lengths between 20 and $40 \mathrm{~cm}$ were tested and it was verified that for lengths less than $30 \mathrm{~cm}$, mixing between sample and electro- lyte was incomplete and led to irreproducible signals. On the other hand greater lengths of the mixing coil significantly compromise the sampling rate. Therefore a $30 \mathrm{~cm}$ reactor length was selected.

With these optimised parameters, the FIA-EC system allowed sam- pling rates of about 115 samples per hour. A linear calibration range for codeine, between 7 and $50 \mathrm{mmol} \mathrm{L}^{-1}$, and a detection limit of $3 \mathrm{mmol} \mathrm{L}^{-1}$, evaluated as the concentration corresponding to three times the standard deviation of the background signal, ${ }^{[11]}$ were obtained.

Interferents on the Determination of Codeine in Pharmaceutical Preparations

In order to evaluate the quality of the results obtained with the voltammetric method and with the FIA manifold determinations were performed using commercially available pharmaceutical preparations. However, although in some European countries pharmaceutical formula- tions exist containing only codeine as active substance, in other countries, such as Portugal and Belgium, it appears associated with active ingredients such as acetaminophen, acetylsalicylic acid (ASA) or caffeine. For this 
reason a study of the possible interference of these compounds in the determination of codeine by SWV and FIA-EC was carried out.

The oxidation behaviour of acetaminophen was evaluated at $\mathrm{pH} 3$ and 6 and one oxidation peak was observed at a potential lower than that observed for codeine at this $\mathrm{pH}$ with a potential separation between the oxidation peaks near $500 \mathrm{mV}$. So if acetaminophen and codeine were present in the same concentration in the pharmaceutical formulations this would not cause any problem to use the SWV method. However, the concentration of acetaminophen in pharmaceutical formulations is approximately 50 times higher than the concentration of codeine. This means that the peaks will overlap making the quantitative determination of codeine using SWV or FIAEC impossible.

Other compounds, such as guaiacol and parabens, that appear in some pharmaceutical preparations together with codeine also present oxidation peaks at lower oxidation potentials than codeine. But since their con- centration is similar to the concentration of codeine in pharmaceutical preparations and the peaks are well separated, it is possible to use the SWV method for codeine quantification.

The oxidation behaviour of other constituents that appear commonly with codeine was also studied. It was verified that ephedrine and acetyl- salicylic acid do not have any oxidation peak at the pHs studied. Caffeine, another compound very often used, has an oxidation peak at potentials higher than that of codeine so that there is no interference in determinations using SWV or FIA-EC.

\section{Determination of Codeine in Pharmaceutical Preparations}

For the evaluation of the developed SWV and FIA-EC methodology, five pharmaceutical preparations containing codeine were chosen, three from Portugal and two from Belgium, Table 1.

The FIA system was calibrated as described and Fig. 5 shows the results obtained in the determination of codeine in pharmaceutical prepara- tions, corresponding to the injection in triplicate of five standard solutions and three samples.

The accuracy of the results provided by the developed SWV and FIA-EC methodology $(C D)$ was assessed by comparing them with the results obtained from the reference methods $(C R)$, i.e., HPLC for oral solutions and titrimetry for tablets. ${ }^{[1]}$ The relative standard deviation of the proposed methodologies was always lower than $4 \%$. Table 1 lists the mean results obtained for three replicate determinations of five pharmaceutical prepara- tions commonly available in Portugal and Belgium. 
Table 1. Determination of Codeine in Commercial Pharmaceutical Preparations Using the Square Wave Voltammetric Method (SWV), FIA with Amperometric Detection, and the Reference Method (HPLC for Oral Solutions and Titrimetry for Tablets ${ }^{[1]}$ )

\begin{tabular}{|c|c|c|c|c|}
\hline Formulation & $\begin{array}{c}\text { Codeine Nominal } \\
\text { Content } \\
\text { EC }^{\mathrm{a}}\end{array}$ & $\mathrm{SWV}^{\mathrm{a}}$ & FIA- & $\begin{array}{l}\text { Reference } \\
\text { Method }^{\mathrm{a}}\end{array}$ \\
\hline Sedotusse $^{\mathrm{b}}$ & $450 \mathrm{mg} 172 \mathrm{~mL}^{-1}$ & $260.0 \pm 6.4$ & - & $258.1 \pm 4.3$ \\
\hline Vacalibom $^{\mathrm{V}}$ & $47 \mathrm{mg} 100 \mathrm{~mL}^{-1}$ & $50.0 \pm 0.6$ & - & $49.1 \pm 0.5$ \\
\hline Dolviran ${ }^{\mathrm{C}}$ & $10 \mathrm{mg}$ tablet $^{-1}$ & $9.5 \pm 0.2$ & $9.7 \pm 0.1$ & $9.7 \pm 0.4$ \\
\hline Codis $^{\mathrm{C}}$ & $8 \mathrm{mg} \mathrm{tablet}^{-1}$ & $8.4 \pm 0.2$ & $8.2 \pm 0.1$ & $8.1 \pm 0.3$ \\
\hline Nogrimine $e^{\mathrm{C}}$ & $30 \mathrm{mg} \mathrm{tablet}^{-1}$ & $29.4 \pm 0.4$ & $30.6 \pm 0.4$ & $30.2 \pm 0.6$ \\
\hline
\end{tabular}

$\mathrm{a}_{\text {Mean and standard deviations of } 3 \text { determinations for different samples (mg tablet }}{ }^{-1}$ or $\left.\mathrm{mg} 100 \mathrm{~mL}^{-1}\right)$; ${ }^{\mathrm{b}}$ Oral solutions containing guaiacol, parabens and ephedrine;

$\mathrm{c}_{\text {Tablets containing codeine, ASA and caffeine. }}$

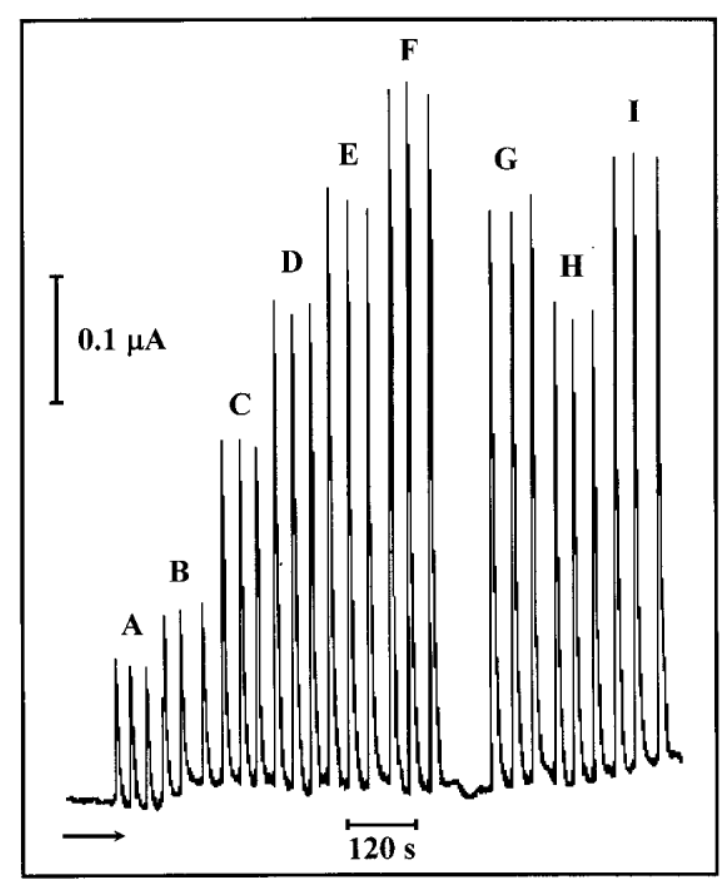

Figure 5. Flow injection analysis with amperometric detection of $\mathrm{mmol} \mathrm{L}^{-1}$ codeine standards solutions: A-7.39, B-10.1; C-20.2, D-30.2, E-40.3, F-50.4, and pharmaceutical samples: G-Dolviran, $\mathrm{H}-$ Nogrimine, and $\mathrm{I}-$ Codis, under the experimental conditions described. 
With this set of values, applying an orthogonal least squares fitting, in all cases a linear relationship is obtained $\left(C_{D^{1 / 4}} C_{0} \mathrm{p} S C_{R}\right.$, with $C_{0}{ }^{1 / 4}-0.8$ and $\left.S^{1 / 4} 1.04\right)$ showing that there is a good agreement between the developed methods and the reference methods. The experimentally determined calibra- tion parameters were compared, with the theoretically expected values by means of Student's $t$-test and, for a confidence interval of $95 \%$, a value of $t$ lower than the critical value was obtained. The repeatability of the methods was evaluated by performing eleven consecutive determinations of each of the solutions to be analysed. The relative standard deviations obtained were less than $3 \%$.

\section{CONCLUSIONS}

The use of electroanalytical techniques SWV or FIA-EC with a glassy carbon electrode for codeine quantification in pharmaceutical preparations proved to be a good alternative for the determination of codeine in most pharmaceutical preparations since it enables a fast, sensitive and selective analysis. Moreover, both proposed methods are simple, easy to operate, inexpensive and made unnecessary complex pre-treatment of the samples unnecessary. The results obtained suggest that this methodology could replace time-consuming and costly procedures and be easily implemented in any routine analytical laboratory.

\section{ACKNOWLEDGMENTS}

One of us (J. M. P. J. G.) would like to thank the PRODEP Program Ph.D. grant. We would like to thank Ms. Iris Van Den Steen for her help with some of the routine work. We also wish to thank M. J. Paiva and

M. Lima for their help.

\section{REFERENCES}

1. British Pharmacopoeia 2000, Vol. 2; HM Stationery Office: London, 2000; 1844.

2. U.S. Pharmacopoeia 2000; US Pharmacopeial Convention Inc.: Rockville, 2000; 171. 1979, 104,620-625.

3. Elsayed, M.A.-H.; Belal, S.F.; Elwalily A.-F.M.; Abdine, H. Analyst 
4. Ramos Martos, N.; Molina Dí az, A.; Navalo’n, A.; Capita’n-Vallvey, L.F. Anal. Lett. 2001, 34, 579-595.

5. Elnemma, E.M.; Hamada, M.A. Mikrochim. Acta 1997, 126, 147-151. 6.

Amin, A.S.; Zareh, M.M. Monatsh. Chem. 1996, 127, 1123-1130.

7. Hofmann, U.; Seefried, S.; Schweizer, E.; Ebner, T.; Mikus, G.; Eichealbaum, M. Biomed. Sci. Appl. 1999, 727, 81-88.

8. Baiulescu, G.E.; Popescu, S.D. Anal. Lett. 1986, 19, 587-596.

9. Zen, J.-M.; Chang, M.-R.; Chung, H.-H.; Shih, Y. Electroanalysis $1998,10,536-540$.

10. Alegret, S.; Alonso, J.; Bartroli, J.; Machado, A.A.S.C.; Lima, J.L.F.C.; Paulis, J.M. Quim. Anal. 1987, 6, 278-294.

11. Analytical Methods Committee, Royal Society of Chemistry. Analyst 1987, 112,199-204.

12. Electrochemical Detection in HPLC, Metrohm, Herisau, 1984.

13. Lima, J.L.F.C.; Rangel, A.O.S.S. J. Int. Sci. Vigne Vin 1990, 24, 49-61. 